\title{
Pornography Cybercrime in the Qatari Cybercrime Law
}

\author{
${ }^{1}$ Ayman Alkrimeen \\ ${ }^{1}$ Assistant Professor of Criminology, Police Academy, Qatar
}

\begin{abstract}
This study deals with pornography cybercrime as organized by the Qatari legislator in the combating cybercrime law No. (14) of 2014, Where the law refers to pornographic crimes related to persons who have not reached the age of eighteen years of age under article (7) thereof, the researcher concluded that the Qatari legislator did not indicate what electronic pornography crime is and its concept accurately, in addition, it does not address pornographic crimes related to the promotion of prostitution, as well as the technical legal aspect of this type of crime.

This study concluded with a series of conclusions and recommendations that were a natural secretion of the research process in this subject and the related concerns, taking into account the issue of the use of computers and various means in rationing those crimes.
\end{abstract}

Key words: Crime, Cybercrime, Pornography Cybercrime, Child Pornography

DOI: $10.7176 /$ JLPG/87-23

Publication date:July $31^{\text {st }} 2019$

\section{Introduction}

The wide spread of the Internet in all countries of the world gave everyone the opportunity to access different websites in all places and times, the Internet has given everyone the opportunity to be a publisher and producer of content in addition to being a consumer, the Internet also plays an important role in the ease of communication with acquaintances, colleagues and friends through video and audio.

There are many advantages and disadvantages to the Internet as a human invention, perhaps the most important of these deficiencies lies in the legal regulatory vacuum exploited by some people in the commission of crimes or negative practices characterized by technology and intelligence, which may affect their symptoms, values or religion. Electronic pornography crime is one of the important crimes that affect people and communities. Because of its material and moral effects affecting the values, morals and symptoms of the victims, it also shows the negative impact of these crimes on society in general, if this problem is not addressed legally. Like other legislators, the Qatari legislature has pursued the overall objective of protecting both its members and society, where the law of cybercrime No. (14) for the year 2014 was introduced, to criminalize and combat cybercrime, including electronic pornography crime.

\section{Study problem}

The Qatari legislator addressed electronic pornography crime in article 7 of the cybercrime law, however, this treatment in law have lacked in some subjects to take into account the practical and technical aspects of electronic means, this may lead to weak protection from the rationing of this text. Consequently, it was necessary to scrutinize this text in order to illustrate it in its forms that help to understand the technical legal aspect, and thus help not to benefit and exploit criminals from the lack of clarity of the text or the rule contained in this text.

\section{The importance of the study}

The importance of this study lies in the seriousness of pornography crimes and their impact on society and victims, from those under 18 years of age or persons with mental or psychological disabilities. Its importance lies in the nature of crimes committed by electronic means, as its study requires the need to take into account the specificity of its nature and its legal organization in terms of criminalization and punishment.

\section{Study Questions}

The study seeks to answer the following questions:

1. What is cyber crime?

2. What is the crime of electronic pornography?

3. What are the characteristics of electronic crimes against children? 
4. To what extent the pornographic electronic crimes are related to the application of general rules?

5. Has the legislator considered criminalizing acts committed against persons with mental and psychological disabilities?

6. Has the legislator taken into account the crime of promoting prostitution and exploitation of children under the age of 18 ?

7. What is the role of Qatari legislation in the face of pornographic electronic crimes?

\section{Objectives of the study}

The purpose of this study is to illustrate the concept of electronic pornography crime and to define its characteristics and elements and its relation to the application of general rules. And knowing the success of the mechanism taken by the Qatari legislator to criminalize this act and impose a number of penalties that are related to the nature of the act committed.

\section{Study Approach}

In this study we relied on the descriptive analytical method and its tools such as books and related studies such as the study of (Allouzi and Thnibat), entitled "Porn offenses as regulated by the Jordanian Information Systems Law, it also relied on the description and analysis of the text contained in the Code of Criminal Procedure of Qatar, in addition to review the views of jurisprudence in this regard.

\section{Study limits}

Spatial Boundaries: Qatar

Time limits: 2019

\section{The study determinants}

In this study, the researcher focuses on identifying electronic pornography crime and its relation to the application of general rules. this is based on the Qatari Criminal Procedure Law No. 14 of 2014 and its amendments of 2017, with the possibility of relying on jurisprudential opinions on the same subject.

\section{Study plan}

In order to address the various problems that have been raised previously, this study is divided into two topics:

The first topic: What is pornography cybercrime?

The second topic: electronic porn crime as regulated by the Qatari legislator in Article (7) of the law against cybercrime.

\section{The first topic}

What are pornography cybercrimes and their relation to the application of general rules?

Attempts differed on a common definition of cybercrime, and this is due to the fast pace of development of electronic technology on the one hand, on the other hand, the role of this technology in crime varies. The information system of this technology is sometimes the subject of crime, and at other times have a way to commit it, whenever the search is for crimes against the information system, the definition starts from the angle of the crime. That it was the crime committed by attacking the information system, whereas if the research is focused on the study of crimes committed using information technology, the focus is on the means as well as on forms of illegal behavior based on the use of computers. ${ }^{1}$

This topic will be addressed in three demands: The concept of cybercrime in the first requirement. The second requirement will clarify the concept of pornography cybercrime. Finally, we will demonstrate the characteristics of pornography cybercrime against children.

\section{The first requirement: the concept of cybercrime:}

The modern computer technology is constantly evolving, which makes it difficult to control the types and images of cybercrime, which made the English legislator in his law issued in 1990 regarding the misuse of the computer, it did not establish a specific definition for these crimes, in order not to limit its criminal base, in

\footnotetext{
${ }^{1}$ Badr Al-Khubaizi, Cybercrime "From a Social Perspective", 1st edition, Kuwait: Dream Book House, 2014, p. 59.
} 
anticipation of future technical and scientific development, leaving jurisprudence and law to determine that with each modernization and technical development of computers, and also with regard to the development and creativity of the information criminal alike. ${ }^{1}$

Several trends of jurisprudence emerged in the definition of cyber crime, including ${ }^{2}$ :

\section{The first trend: based on the subject of crime:}

According to this direction, cybercrime is considered as a crime that occurs on a computer, or in relation to its system, this trend in their definition of cybercrime was based on the fact that computers should be the subject of crime, and not the ones in which computer is her way, and they defined these crimes as: "Illegal activity directed at copying, altering, deleting or accessing information stored inside the computer or turned through it" what is taken in this direction is that it has adopted an objective criterion in which the acts relating to computer crimes are not precisely defined.

The second trend: relying on the means of committing the crime:

The proponents of this trend are based on the means of committing the crime, where they stipulated that they should be committed by computer, and they defined cybercrime as: "All forms of unlawful (or detrimental to society) behavior committed using the computer".

Another definition of cybercrime, identical to it defined as "Every criminal act is done using a computer as the main tool."

\section{The third trend: It was based on the offender of the crime (The culprit).}

This trend in defining cybercrime was based on a personal criterion that requires the perpetrator to be knowledgeable about information technology and how to use computers. As an example of David Thompson's definition of computer crime, he defined it as: "Any crime that requires a perpetrator to have knowledge of computer technology."

The US Department of Justice also defined computer crime as: "Any crime whose actor has a technical knowledge of computers that enables him to commit it."

\section{The fourth trend: No standard is defined in the definition of cybercrime}

For example, some have defined that cybercrime: "These are the crimes resulting from the use of information and modern technology of computer and internet in criminal acts and activities. They are usually committed with the aim of generating huge financial returns from illegal actions that are re-injected into the international economy via the Internet. " economic cooperation experts in Europe have defined cybercrime as "any unlawful, immoral or unauthorized conduct associated with the automatic processing or transfer of data". ${ }^{3}$

The Qatari legislator referred to Article 1 of the Law on Combating Cybercrime to the means by which the crime is committed in the first article of the Code of combating cybercrime, connecting them using the information system in the information network, the information system is defined as: "A set of software and hardware, used to create, extract, transmit, receive, display, process or store information." he also defined the information network as: "A link between more than one means of information technology, for access to and exchange of information, including private and public networks and the global Internet"4. From the above, the researcher finds that the statement of what cybercrime is one of the dilemmas facing legislators, jurists and the explanation of the law, in the developing a comprehensive concept that prevents an agreed definition is difficult and challenging the different legislation between states, accordingly, the researcher can develop a definition commensurate with the nature of cybercrime and the mechanism of using electronic means, as follows: Cybercrime is: "Every illegal activity is on the computer, or about his system, issued by someone who is knowledgeable about information technology and how to use the computer, provided that the computer is used as the main tool, regardless of the manner in which the crime was committed, or the purpose of its commission.

\footnotetext{
${ }^{1}$ Mariam Othman Abdulqader, Criminal Protection of Children from Cybercrime, 1st edition, Dubai: Dubai Academy Publishing House, 2014, p. 66.

${ }^{2}$ Mohammed Ahmad Ababneh, Computer Crimes and its International Dimensions, 1st edition, Amman: Dar Al Thaqafa for Publishing and Distribution, 2015. See also Mariam Othman Abdulqader, Criminal Protection of Children from Cybercrime, 1st edition, Dubai: Dubai Academy Publishing House, 2014, pp. 67-70.

3 Abdullah Abdulkarim Abdullah, Cybercrime and the Internet, a comparative study in the legal system to combat cybercrime, 1st edition, Beirut: Halabi publications, 2007, p. 15

4 Qatari Anti-Cybercrime Law No. (14) of 2014
} 
The second requirement: The concept of pornographic electronic crimes

Pornography is defined within the general standard of the model legislation, any definition of these articles should include, at a minimum, the following: Visual depiction or images that represent a child participating in a display, activity or sexual show (real or simulated), in addition, there may be words or phrases within the definition of child pornography that need clarification. For example, definitions of terms such as: Explicit sexual act and any offer, conduct or sexual act ${ }^{1}$. As for the Council of Europe Convention on Cybercrime, article 9, paragraph 2 (a), defines pornography exploited for children as: Any pornography visualize in a visual manner a minor exhibits sexual behavior. In paragraph (3) of the same article, the minor is defined as: Any person under the age of $18^{2}$. Spreads across the Internet the so-called "electronic porn", where scandalous photographs are exchanged freely through this network, and there are porn clubs in the West that operate on the World Wide Web. Some have defined sexual pornography in the media as: "Every violation is committed by the use of visual and auditory technologies against the private secrecy of the human body, Male or female, and would make the human person and the human body, a commodity for a bad need for pleasure ${ }^{3}$. Explicit pornographic or sexual content is not homogeneous in nature, it is considered multifaceted, ranges from partial nudity, to an inexplicit sex, then an explicit sex, to other qualitative characteristics including violence, masochism, collective sex, and the real or implicit exploitation of children sexually ${ }^{4}$.

The definition of pornography seems to be a seemingly simple task but the truth is none of that, definitions associated with such content are socially, politically and culturally relevant to the environment surrounding the definition, thus there is no uniform consensus on their definition. Some research has provided a simple definition of it: "Any sexually explicit representation". On the other hand we find those who are required to define it (Watch porn), and this is referred to in the text of the Supreme Court "I am unable to define pornography, but I can know it when I see it". 5

There are many acts that affect children, which require criminalization and punishment for seriousness, for example

1. The crime of deliberate viewing of pornographic acts involving children.

2. Crimes committed by parents or guardians who consent to the participation of their children in pornography.

3. Luring children as a first step in order to prepare him for a sexual relationship.

4. The responsibility of Internet service providers, measured by those working in the health and social service sectors, teachers, photo developers, information technology workers, credit card companies and banks, measured by those working in the health and social service sectors, teachers, photo developers, information technology workers, credit card companies and banks, these entities are committed to inform the concerned authorities for any suspicious child pornography (mandatory reporting).

\footnotetext{
1 International Center for Missing and Exploited Children, Child Pornography: Model Legislation and the Global Legislation Review, 7th edition, 2013, p. 7.

2 Najat Mualla Majeed, promotion and protection of all human rights, civil, political, economic and social, including the right to development, Report to the UN General Assembly, Human Rights Council, 12th Session, 2009, pp. 8-9.

3 Dima Omar Marei, Combating Pornography Web Sites: The Problem, Impact and Control Methods, 1st edition, Cairo: Arab World House, 2013, p. 153. See also: Kirstie Cope-Farrar \& Dale Kunkel, Sexual Messages in Teens Favorite Prime-Time Television Programs, IN, Jane Brown \& Other: Sexual Teens, Sexual Media Investigating Medias Influence on Adolescent Sexuality, (London: Lawrence Erlbaum Associates, 2008, Pp: 59-61.

4 Wafik Safwat Mokhtar, Communication, media and the Formation of Children and Youth Awareness, 1st Floor, Cairo: Dar Gharib for Printing, Publishing and Distribution, 2010, p. 78. See also: Laura Salazar \& Et al: Sexually Explicit Content Viewed by Teens on the Internet, Op. Cit., Pp: 115-118.

5 Michael Patriek: The Effect of Source and Relation Priming on the relationship between pornography exposure and attitudes toward sex, women and rape, Op. Cit., P10.

6 Ahmad Mohammed Al-Lawzi and Mohammed Abdul Majeed Al-Dhunaibat, Cybercrime as Organized by the Jordanian Information Systems Crimes Law, Faculty of Sharia and Law Sciences, Middle East University, Vol. 42, No. 3, 2015 , p. 842.
} 
The Qatari legislator has dealt with pornography in Article (7) of the Law on Combating Cybercrime, where he defined electronic pornography crime as "those crimes resulting from the production of child pornography by means of information technology ${ }^{1}$, accordingly, the researcher can develop a definition of electronic pornography crime appropriate to the nature of the crime and legal adaptation to it, as follows:

Every act or refrain from doing aims to create sexual arousal for Internet users, it refers to sexual material available electronically via the Internet through various websites, using any means of technology, whether the method used is traditional by viewing magazines that contain pornography or unconventional, through magazines that contain blatant images or through discussion groups (chat rooms) or a library show that includes film and sex video clips, some are commercial and others are free.

\section{Third requirement: Characteristics of cyber crimes against children}

In this requirement, I will address the characteristics of cybercrime against children; however, in presenting these characteristics as a whole, I must refer to the characteristics of cybercrime in general in order to distinguish them from other cybercrime.

First: the characteristics of cyber crimes and distinguish them from other crimes:

There are characteristics that cybercrime shares with other conventional crimes represented in the seriousness of cybercrime in that it affects the human in his own thought and life, and also touch the institutions in their economy, and the country in its national, political and social security ${ }^{2}$.

In the Internet community, the geographical boundaries between countries are dissolved because the world is connected to a single network. Most cybercrime involves the perpetrator in one country and the victim in another. Hacking of computer systems may occur outside the territory of the victim's state, the damage caused by the crime is not limited to the victim alone, but also to other victims in multiple States ${ }^{3}$.

Cybercrime has characteristics that are unique to other crimes, the most important ${ }^{4}$ :

1. That a computer is a tool or place for committing cybercrime, where he became the main means of carrying out these crimes whether it was a place of assault, such as software theft, tampering with computer data or stored information, or be a means of assaulting private life, such as money-related crimes.

2. Cybercrime is characterized that it committed in a hidden and hidden way, by spying online and sending viruses via email.

3. Cybercrime does not rely on violence in execution, it does not require a violent effort from the perpetrator, for the damage caused it does not need the same violence as conventional crimes.

4. Diversity of motivation to commit cybercrime which may help prove it, the motivation may be material gain or proof of scientific excellence, or revenge, the motivation may be just entertainment, fun and humor.

\section{Second: Characteristics of cyber crimes against children:}

Cybercrime against children has characteristics that are unique to other cybercrime, among them are ${ }^{5}$ :

1. This crime targets the category of children, where they are subjected to all kinds of exploitation, and the perpetrators of these crimes do not count a certain age for children to be exploited.

\footnotetext{
${ }^{1}$ Qatari Anti-Cybercrime Law No. (14) of 2014.

2 Mohammad Sami Al-Shawa, The Information Revolution and Its Implications for the Penal Code, Dar Al-Nahda Al-Arabiya, 1994, p. 19

3 Mohammed Abdul Rahim Sultan, Cybercrime and its Computation, Arab Journal for Security Studies and Training, Volume 18, No. 36, 2003, pp. 28-29

4 Amir Farag Youssef, Cybercrime and International and Local Efforts to Combat Computer Crimes and Communications, Al-Wafa Legal Library for Publishing, 1st edition, Alexandria, 2011, pp. 12-19

5 Mohammed Al-Amin Al-Bishri, Ibrahim Al-Hinai, A study on cybercrime and ways to confront it, Publications of the Security Research and Studies Center, Dubai Police, 2008. See also Amir Faraj Yousef, op. Cit., Pp. 12-19.
} 
2. Cybercrime for children requires sufficient knowledge of technical skills and knowledge, such as the technical knowledge of the computer, and how to operate and use.

3. Cybercrime against children is a transnational crime, like ordinary cybercrime, where the exploitation of children from professional criminals, for example pornographic websites, this network is open and global, its services are to offer and download sex movies for free, and some of these sites target children of a certain age to raise them sexually.

4. The rapid development of cybercrime methods against children, and its relevance to the rapid developments we are witnessing today in information and communication technology, and everything about updating websites, for example, organized crime, such as child prostitution, and the screening of pornographic movies and online gaming sites that show pornographic images provoke the child's instinct.

5. Most cybercrime against children is motivated by material gain, where the perpetrators of these crimes exploit children by producing pornographic images for children to sell through the computer system at high prices to interested people, like homosexuals, it is also motivated to commit these crimes is a sense of inferiority, where an individual commits this act to prove himself, the motive may be to demonstrate scientific excellence, the idea of challenge and the ability to commit the crime.

6. Many relatives of victims are hesitate to report cybercrime against their children, because publishing and advertising these crimes further damages the reputation of victims, especially as children. Because publishing and advertising these crimes further damages the reputation of victims, especially as children.

\section{The second topic}

\section{Cybercrime}

Electronic pornography crime as regulated by the legislator in Article 7 of the Law on Combating

Article 7 of the Qatari Anti-Cyber Crime Law stipulates the criminalization of electronic porn acts in respect of persons under 18 years of age, where the text reads as follows: Shall be punished by imprisonment for a term not exceeding five years, with a fine not exceeding $(500,000)$ five hundred thousand riyals, whoever produced pornography about a child by means of information technology, import, sell, offer for sale, use, trade, transmit, distribute, send, publish, make available or transmit child pornography by means of information technology.

He shall be punished with imprisonment for a period not exceeding one year and a fine not exceeding 250,000 two hundred and fifty thousand riyals, or one of these penalties, whoever has pornography about a child. The consent of the child shall not be counted in the offenses punishable in this article. And any person who has not attained the age of eighteen years shall be considered a child under this article."

Accordingly, this study will examine and analyze the previous text through three demands as follows: First requirement: the transmission or dissemination of electronic pornography relating to persons under 18 years of age; second, we will review electronic pornography crime related to prostitution and sexual exploitation. The third requirement clarified the use of technology in electronic pornography crime and how it is displayed.

First requirement: Send or publish electronic pornography related to those who have not reached the age of eighteen years

\section{First: Definition of the child:}

International legislation and conventions went on to define the child as: "Anyone under the age of 18". This is reflected in the model legislation relating to the fight against pornography related to children. ${ }^{1}$

Second: The subject of Pornography crime:

By scrutinizing the text of Article (7) of the Anti-Cybercrime Law, the researcher believes that the legislator has pointed out that the subject of the crime is the material or pornography that contains a person who has not reached the age of eighteen years, consequently, it has criminalized the transmission or dissemination of

\footnotetext{
1 Osama Ghanem Al-Obeidi, The Crime of Sexual Exploitation of Children Online, Journal of Sharia and Law, College of Law, United Arab Emirates University, Year 27, Issue 53, 2013, pp. 84-85.
} 
any pornography in which it is involved or related to the exploitation of persons under 18 years of age. This is to protect the dignity and innocence of those under 18.

The legislator referred to the terms of transmission and dissemination without distinguishing between them as criminal offenses, because the physical corner of the crime is available in them, is it true that transmission as an act is the same in terms of action and impact?

The researcher considers that transmission -As the legislator meant it (Limited access to pornographic material) The essence of crime (With a person or group of people).

Publication is intended here about opening the door to as wide an audience as possible- Whether or not it was linked to a material benefit- Thus completing the element or public corner of the crime. As stated in Article (16) of the Qatari Penal Code ${ }^{1}$.

Third: the method of transmission and dissemination:

The researcher also finds in the text above that the legislator has not specified a method of transmission or publication, here, the researcher believes that the legislator did better when he did not specify a specific method of transmission or publication, this is because of the difference between the methods used, some of them are of a technical nature and others are of a programmatic nature.

As the legislator did not mention to the way pornography is published, is it transmitted or disseminated by technical means in an audible, readable or visual manner, here, the researcher thinks it would have been better for the legislator to touch on that, in order to avoid spreading outrageous and provide the most effective legal protection.

Fourth: criminal intent

With regard to criminal intent, the researcher finds that the legislator did not explicitly mention this in the text of the previous article regarding transmission or publication. It is understood that criminal intent is a major corner that must be available in criminalization and punishment, the perpetrator must have the intention and knowledge of the consequence of his act, after which the act shall be considered intentional, the intention here is for the offender to cause harm (Material or moral) to his victim by sending or disseminating pornography through an information system or information network, to have access to the material or pornography by the addressee, recipient, or interested person of publication, this act is distinct from possession the perpetrator is engaged in an act to leads to the circulation of matter, or pornography, it was therefore necessary to punish the offender for his intended act of transmission or publication ${ }^{2}$, as addressed in the previous article

Second requirement: Cybercrime related to sexual exploitation and prostitution:

Exploitation means: "Every use is intended to offend"3, if the exploitation is linked to the purpose of the offender intended to the victim whether a person who has not attained the age of eighteen years of age or is mentally disabled for lack of eligibility or lack thereof. The intended use of the above definition is intended to create or achieve a criminal offense punishable by law, thus abuse is achieved through the use of incompetent or disqualified for this purpose. The international legislation has dealt with the statement of exploitation according to a set of terms with a view to defining child pornography, which: The exploitation of children in pornography, and sexual orientation to children, and pornography exploited for children, And pornography related to events, and pornography based on imitating children, and pornography simulation-based, and computer-generated pornography, and pornography and online sexual abuse, and the exploitation of children in sexual arousal, etc. ${ }^{4}$

However, the researcher did not find that the Qatari legislator has addressed the participation of those under the age of 18 in pornography and to be guaranteed for sexual exploitation. Since there is a difference between the participation and sexual exploitation of those under the age of 18, pornography can contain a person who has not yet attained the age of 18 and is aware of the nature of the work, while in the process of exploitation no voluntary or cognitive, or be voluntarily tainted In terms of will, those under the age of eighteen Suffering

\footnotetext{
${ }^{1}$ Article (16) of the Qatari Penal Code stipulates that the provisions of this law shall apply to:1 He has committed outside Qatar an act that makes him an accomplice or partner in a crime that took place in whole or in part in Qatar. 2 Committed within Qatar an act that makes him an actor or a partner in a crime that took place in whole or in part outside Qatar, when it was punishable under this law and the law of the country in which it occurred.

2 Ahmad al-Lawzi and Muhammad al-Thunaibat, Previous reference, P. 838

3 The Dictionary of the Arabs (meaning from the rich dictionary), http: // www. Arabdict.com.

${ }^{4}$ Najat Mu'alla Majeed, Previous reference, P. 7.
} 
from mental or psychological disabilities, have been subjected to sexual exploitation or pornography, the legislator did not address that category, where it was first interest in that category.

With regard to the criminalization of prostitution, the researcher finds that the previous text was incomplete in terms of inclusiveness, this implies the assumption of weak protection to be achieved from the text, he lacked exposure to criminalize prostitution, and therefore not to mention their different forms and how to promote them, this is a legislative failure.

Advocates mean: Every flagrant and debauchery act is committed for a price (Or without a price), in an organized or usual way, with or without discrimination ${ }^{1}$.

It should be noted that the legislator referred to (satisfaction), he stressed in the text of the previous article that: "The offenses punishable in this article shall not be considered child consent. A child under the provisions of this Article shall be deemed a child who has not been eighteen years of age.

The third requirement: The use of the means of technology in electronic pornography crime and how to display it

Looking at the previous text, the researcher finds that the legislator mentioned the word use, but he didn't mention the preparation, because the legal effect is withdrawn to both phases whether it's (by preparing or working on usability), criminalization must include the preparation of any pornographic act or activity, in addition to working on the usability in a manner commensurate with the nature of the use of the information system or information network as a means to be used in crime ${ }^{2}$.

As for the view of electronic pornography, the legislator did well when referring to the text of the previous article as saying: Whoever offers to sell pornographic material about a child by means of information technology, what is meant here is: Allow work or activity to be submitted to the specified category, whether it's on request or without it, and in a usable way in the offense. To have access to the criminal material or work which in turn represents an agitation tool, or guidance to commit a crime.

\section{Conclusion}

The weakness of the legal framework related to the technical or practical aspect, it is considered one of the most important obstacles facing the legislation related to cybercrime, especially pornographic crimes in the Arab world -Qatar- As one of these countries, they face the same obstacles connected to that side. Electronic pornography crime poses a threat to all segments of society, beyond the codification phase of the legislative text regulating that crime as regulated by the law against cybercrime in Article 7 thereof. In line with international and Arab requirements and agreements, however, this text does not take into account the technical and practical aspects in terms of concept and nature; in addition, the Qatari legislator omitted a number of practices that should be included in the text (the subject of the study).

This study illustrates the concept of electronic pornography crime and the related legal and technical aspects, whereas the text of the article (the subject of the study) and the law in its entirety are devoid of any definition of what electronic pornography crime is, this necessitated the use of a definition or attempt to define the nature of this type of crime, in addition, the text contains a set of rules and provisions that criminalize a number of acts with a view to establishing legal protection for members of society. However, the legislator has failed in the legislation on those under the age of 18 who suffer from a mental or psychological disability, in codifying this text, he also did not distinguish between acts and their nature as previously explained.

Accordingly, the study has reached a number of results which we summarize in the following points:

1. The Qatari legislator addressed electronic pornography crime in Article 7 according to two criteria;

2. The first (general) criminalizes pornography, the second dealt with child pornography crimes under the age of 18 , without addressing children with mental or psychological disabilities.

3. There is no definition in the Qatari anti- Cybercrime low that defines the nature of pornographic crimes, and this creates a legal gap related to the nature and characteristics of the crime.

\footnotetext{
${ }^{1}$ Ahmad al-Lawzi and Muhammad al-Dhunaibat, previous reference, P. 837.

2 International Center for Missing and Exploited Children, Previous reference, Pp. 3-4
} 
4. The Qatari legislator criminalized in article 7 of the law against cybercrime any act or action affecting those under 18 years of age in a manner that is close to the norms of international legislation, and the legislator did well in that, however, the researcher believes that the text did not fulfill some important issues related to the category of persons with mental and psychological disabilities their right to impose the appropriate punishment and the nature of the act.

5. The legislator stated in the text of Article VII of the same law that he does not count in the crimes punishable in this article the consent of the child, and the researcher believes that the legislator has done well in this.

6. The legislator has not criminalized any act related to the promotion of prostitution, he also does not identify specific issues such as those that lead to the prostitution industry in a manner that satisfies the purpose of criminalization.

7. The legislator did not provide in the article mentioned any responsibility attached to the Internet service providers for any act related to sexual abuse of children related to sexual exploitation.

8. The lawmaker criminalized possession of child pornography and he decided to have a penalty of imprisonment for a period not exceeding one year, with a fine not exceeding (250.000) two hundred and fifty thousand riyals, or one of these two penalties.

9. There are many images of child pornography not addressed by the legislator in the anti-Cybercrime low, examples include: Deliberate viewing of child pornography involving children with mental or psychological disabilities, or coercing children into child pornography.

\section{Recommendations}

1. The researcher wishes the legislator to provide a definition of the nature of cybercrime.

2. The researcher recommends the need to add a proposal related to (criminalization of electronic prostitution), as a text dealing with acts of an organized or collective nature or a special situation, in order to achieve the necessary protection.

3. The need to explicitly provide for the sexual exploitation of children and children with mental or psychological disabilities; and distinguish between the acts of participation and exploitation in the prescribed penalty.

4. The researcher considers it necessary to expand the scope of Article (7) with regard to preparing for the commission of the crime. To prepare for this, with a view to ensuring better protection for the category to be protected.

5. The researcher recommends that the legislator address in the text of Article 7 other images of cybercrime. Especially related to a child that hasn't been touched, such as: (A) The crime of deliberate viewing of pornographic acts involving children or acts of parents who consent to the participation of their children in pornographic material. (B) Criminalizing the attraction of children to engage in sexual acts, like other offenses established by law.

\section{References}

(1) Badr Al-Khubaizi, Cybercrime "From a Social Perspective", 1st edition, Kuwait: Dream Book House, 2014, p. 59.

(2) Mariam Othman Abdulqader, Criminal Protection of Children from Cybercrime, 1st edition, Dubai: Dubai Academy Publishing House, 2014, p. 66.

(3) Mohammed Ahmad Ababneh, Computer Crimes and its International Dimensions, 1st edition, Amman: Dar Al Thaqafa for Publishing and Distribution, 2015. See also Mariam Othman Abdulqader, Criminal Protection of Children from Cybercrime, 1st edition, Dubai: Dubai Academy Publishing House, 2014, pp. 67-70. 
(4) Abdullah Abdulkarim Abdullah, Cybercrime and the Internet, a comparative study in the legal system to combat cybercrime, 1st edition, Beirut: Halabi publications, 2007, p. 15.

(5) Qatari Anti-Cybercrime Law No. (14) of 2014.

(6) International Center for Missing and Exploited Children, Child Pornography: Model Legislation and the Global Legislation Review, 7th edition, 2013, p. 7.

(7) Najat Mualla Majeed, promotion and protection of all human rights, civil, political, economic and social, including the right to development, Report to the UN General Assembly, Human Rights Council, 12th Session, 2009, pp. 8-9.

(8) Dima Omar Marei, Combating Pornography Web Sites: The Problem, Impact and Control Methods, 1st edition, Cairo: Arab World House, 2013, p. 153. See also: Kirstie Cope-Farrar \& Dale Kunkel, Sexual Messages in Teens Favorite Prime-Time Television Programs, IN, Jane Brown \& Other: Sexual Teens, Sexual Media Investigating Medias Influence on Adolescent Sexuality, (London: Lawrence Erlbaum Associates, 2008, Pp: 59-61.

(9) Wafik Safwat Mokhtar, Communication, media and the Formation of Children and Youth Awareness, 1st Floor, Cairo: Dar Gharib for Printing, Publishing and Distribution, 2010, p. 78. See also: Laura Salazar \& Et al: Sexually Explicit Content Viewed by Teens on the Internet, Op. Cit., Pp: 115-118.

(10) Michael Patriek: The Effect of Source and Relation Priming on the relationship between pornography exposure and attitudes toward sex, women and rape, Op. Cit., P10.

(11) Ahmad Mohammed Al-Lawzi and Mohammed Abdul Majeed Al-Dhunaibat, Cybercrime as Organized by the Jordanian Information Systems Crimes Law, Faculty of Sharia and Law Sciences, Middle East University, Vol. 42, No. 3, 2015, p. 842.

(12) Qatari Anti-Cybercrime Law No. (14) of 2014.

(13) Mohammad Sami Al-Shawa, The Information Revolution and Its Implications for the Penal Code, Dar AlNahda Al-Arabiya, 1994, p. 19.

(14) Mohammed Abdul Rahim Sultan, Cybercrime and its Computation, Arab Journal for Security Studies and Training, Volume 18, No. 36, 2003, pp. 28-29.

(15) Amir Farag Youssef, Cybercrime and International and Local Efforts to Combat Computer Crimes and Communications, Al-Wafa Legal Library for Publishing, 1st edition, Alexandria, 2011, pp. 12-19.

(16) Mohammed Al-Amin Al-Bishri, Ibrahim Al-Hinai, A study on cybercrime and ways to confront it, Publications of the Security Research and Studies Center, Dubai Police, 2008. See also Amir Faraj Yousef, op. Cit., Pp. 12-19.

(17) Osama Ghanem Al-Obeidi, The Crime of Sexual Exploitation of Children Online, Journal of Sharia and Law, College of Law, United Arab Emirates University, Year 27, Issue 53, 2013, pp. 84-85.

(18) Article (16) of the Qatari Penal Code stipulates that the provisions of this law shall apply to: $1 \mathrm{He}$ has committed outside Qatar an act that makes him an accomplice or partner in a crime that took place in whole or in part in Qatar. 2 Committed within Qatar an act that makes him an actor or a partner in a crime that took place in whole or in part outside Qatar, when it was punishable under this law and the law of the country in which it occurred.

(19) Ahmad al-Lawzi and Muhammad al-Thunaibat, Previous reference, P. 838.

(20)The Dictionary of the Arabs (meaning from the rich dictionary), http: // www. Arabdict.com.

(21) Najat Mu'alla Majeed, Previous reference, P. 7.

(22) Ahmad al-Lawzi and Muhammad al-Dhunaibat, previous reference, P. 837.

(23) International Center for Missing and Exploited Children, Previous reference, Pp. 3-4 